\title{
Synthesis and characterization of branched polysaccharides by reaction of cellulose with $2,3,4,6$-tetraacetyl-1-bromo- $\alpha$-D- glucopyranoside
}

\author{
Andreas Koschella, ${ }^{a}$ Susann Dorn, ${ }^{\text {a }}$ Thomas Heinze, ${ }^{\mathrm{a}, \mathrm{b}} *$ Adiaratou Togola, \\ and Berit Smestad Paulsen ${ }^{\mathrm{c}}$ \\ ${ }^{a}$ Friedrich Schiller University of Jena, Institute for Organic Chemistry and Macromolecular \\ Chemistry, Centre of Excellence for Polysaccharide Research, Humboldtstraße 10, D-07743 \\ Jena, Germany \\ ${ }^{b}$ A bo Akademi University, Fibre and Cellulose Technology, Porthansgatan 3, FI-20500 Abo, \\ Finland \\ ${ }^{c}$ University of Oslo, School of Pharmacy, P.O 1068, Blindern N-0316 Oslo, Norway \\ -Member of the European Polysaccharide Network of Excellence (EPNOE), www.epnoe.eu \\ E-mail: thomas.heinze@uni-jena.de
}

Dedicated to Prof. Dr. Rainer Beckert on the occasion of his $60^{\text {th }}$ birthday

\begin{abstract}
Non-naturally branched polysaccharides were prepared homogeneously by reaction of cellulose in $N, N$-dimethyl acetamide/ $\mathrm{LiCl}$ and the ionic liquid 1- $\mathrm{N}$-butyl-3-methylimidazolium chloride with 2,3,4,6-tetraacetyl-1-bromo- $\alpha$-D-glucopyranoside in the presence of triethylamine as base. Degrees of substitution up to 0.58 were realized. The samples were soluble in dimethyl sulphoxide and water. NMR spectroscopy and methylation analysis revealed the formation of 1,2-orthoesters. The purity of the products regarding non-bonded sugar molecules was evidenced by advanced NMR techniques (DOSY- and $\mathrm{T}_{2}$ measurements).

In contrast to the reaction in 1- $N$-butyl-3-methylimidazolium chloride, 1- $N$-ethyl-3methylimidazolium acetate acts not only as solvent but also as reagent and leads to the formation of cellulose acetate instead of the desired product.
\end{abstract}

Keywords: Cellulose derivative, 1,2-orthoester formation, methylation analysis, NMR spectroscopy, diffusion measurement, cellulose solvent 


\section{Introduction}

Cellulose, one of the most abundant polysaccharides, is the feedstock for many biopolymerbased products. Due to the unique structure, cellulose is insoluble in water and common organic solvents. Soluble materials are obtained by appropriate derivatization reactions that are of interest in many application fields. The pendant groups render the polymer soluble in different types of solvents -of course- depending on the type of substituent and the degree of substitution (DS). Esters (e.g., cellulose acetates, propionates, and mixed derivatives) are soluble in organic solvents, while ethers (e.g., methyl, hydroxyalkyl, and carboxymethyl cellulose) dissolve in water at certain DS. The latter ones are often applied as thickening agents in industrial and household applications and as additive in building materials, paints, drilling fluids, food and personal care products. ${ }^{1,2}$ Naturally occurring branched polysaccharides like amylopectin, glucoand galactomannans exhibit water solubility even without derivatization. ${ }^{3}$ Several attempts have been made in order to produce artificially branched polysaccharides. Thus, enzymes have been applied for grafting of glucose onto cellulose yielding materials with improved properties. ${ }^{4}$ Grafting of glucose onto powdered cellulose yields colloidal aqueous dispersions useful as sizing or adhesive agent. Glasser et al. have reacted cellulose in $N, N$-dimethyl acetamide (DMA)/LiCl solution with diethylaminosulfur trifluoride or hydrogen fluoride to introduce long-chain branches by transglycosylation. ${ }^{5}$ Furthermore, the introduction of monosaccharide moieties into the polysaccharides by using reactive intermediates has been studied since a long time. Usually, 2,3-di- $O$-protected cellulose derivatives (2,3-O-esters or 2,3-O-phenylcarbamates) are used for the regioselective glycosylation at position 6 by reacting the polymer with acetobromosugars in the presence of both mercuric compounds ${ }^{6}$ and strong bases. ${ }^{7}$ Moreover, sugar orthoesters were reacted with 2,3-di-O-phenylcarbamoyl cellulose and starch. ${ }^{8,9}$ Several papers describe the introduction of sugar moieties into chitin and chitosan. ${ }^{10-13}$ Branched polysaccharides exhibit interesting properties, in particular bioactivity. Thus, the influence of sugar side chains on the biological activity of clinically used polysaccharides was investigated. ${ }^{14,15}$ Kurita et al. have found that some properties of chitin and chitosan (antimicrobial activity, aggregation ability for bovine serum albumin) are improved after glycosylation reaction with a glucosamino derivative. $^{16}$

In the course of our ongoing work on water-soluble cellulose derivatives, we have reported results on oxidized cellulose derivatives ${ }^{17}$, cellulosics bearing cationically charged moieties, ${ }^{18}$ cellulosics bearing oxocarbonic acid esters of high $\mathrm{DS},{ }^{19}$ carboxymethyl cellulose ${ }^{20}$, and cellulose polyelectrolytes prepared via click-reaction. ${ }^{21}$

For homogeneous chemical modification of cellulose, $\mathrm{DMA} / \mathrm{LiCl}$ developed by McCormick, is a very versatile reaction medium. ${ }^{22}$ Moreover, ionic liquids (IL) gained increasing interest in carbohydrate chemistry, ${ }^{23}$ in particular for esterification ${ }^{24-26}$ and etherification. ${ }^{27}$ However, it was realized that some IL (e.g. 1-N-ethyl-3-methylimidazolium acetate, EMIMAc) may lead to side reactions during esterification with carboxylic acids and the anion is included in the chemical 
modification of the biopolymer. As a consequence, pure cellulose acetate is formed instead of the desired ester. $^{28}$

In this paper we report the reaction of cellulose with 2,3,4,6-tetraacetyl-1-bromo- $\alpha$-Dglucopyranoside under homogeneous conditions in $\mathrm{DMA} / \mathrm{LiCl}$ and IL without the use of silverand mercury salts to yield soluble cellulose derivatives. The structure of the resulting products was investigated by FTIR- and NMR spectroscopy.

\section{Results and Discussion}

The reaction of cellulose was studied under homogeneous conditions using $\mathrm{DMA} / \mathrm{LiCl}$ as classical solvent and the IL 1-N-butyl-3-methylimidazolium chloride (BMIMCl) and EMIMAc. The dissolved polymer was allowed to react with 2,3,4,6-tetraacetyl-1-bromo- $\alpha$-Dglucopyranoside in the presence of triethylamine as acid scavenger (Scheme 1). Precipitation, washing with ethanol, and drying afforded the products as coffee-brown powders. The acetyl group content of selected samples was determined by saponification and titration and used for the calculation of the degree of substitution (DS).

In a first series of experiments, $\mathrm{DMA} / \mathrm{LiCl}$ was used a solvent (Table 1). The reaction of cellulose (degree of polymerization, DP, 30) with 1 mol 2,3,4,6-tetraacetyl-1-bromo- $\alpha$-Dglucopyranoside and $2 \mathrm{~mol}$ triethylamine per mol anhydroglucose unit (AGU) for $24 \mathrm{~h}$ at $50^{\circ} \mathrm{C}$ afforded a product that was soluble in both water and dimethyl sulphoxide (DMSO) (sample 2 , DS 0.35). Repetition of the reaction yielded a sample with DS 0.33 after $20 \mathrm{~h}$ at $50^{\circ} \mathrm{C}$ (sample 3 ).

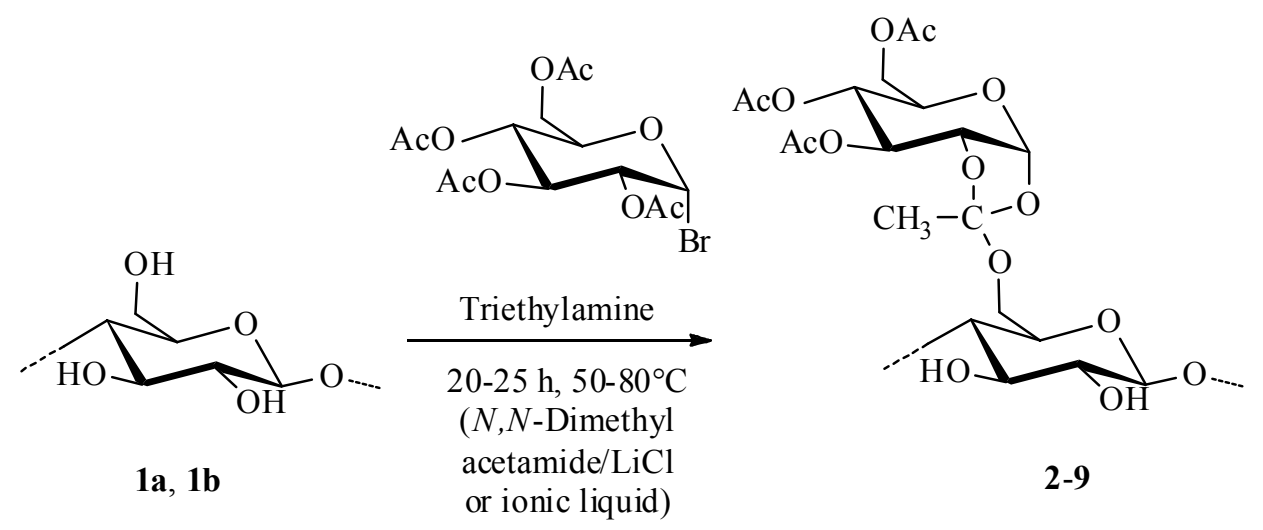

Scheme 1. Reaction scheme for the reaction of cellulose dissolved in $N, N$-dimethyl acetamide/ $\mathrm{LiCl}$ or in the ionic liquids $1-N$-butyl-3-methylimidazolium chloride and 1- $N$-ethyl-3methylimidazolium acetate with 2,3,4,6-tetraacetyl-1-bromo- $\alpha$-D-glucopyranoside under formation 1,2-orthoesters. The degree of substitution of the samples is not considered for clarity reasons $(\mathrm{Ac}=\mathrm{Acety})$. 
Table 1. Conditions for and results of the reaction of cellulose with 3,4,6-tetraacetyl-1-bromo- $\alpha$ D-glucopyranoside in the presence of triethylamine under homogeneous reaction conditions

\begin{tabular}{|c|c|c|c|c|c|c|c|c|}
\hline \multicolumn{5}{|c|}{ Conditions } & \multicolumn{4}{|l|}{ Results } \\
\hline \multirow{2}{*}{$\begin{array}{l}\text { Cellu- } \\
\text { lose }^{\mathrm{a}}\end{array}$} & \multirow[t]{2}{*}{ Medium $^{\mathrm{b}}$} & \multirow{2}{*}{$\begin{array}{l}\text { Molra } \\
\text { ratio }^{c}\end{array}$} & \multirow{2}{*}{$\begin{array}{l}\text { Time } \\
\text { (h) }\end{array}$} & \multirow{2}{*}{$\begin{array}{l}\text { Temper- } \\
\text { ature }\left({ }^{\circ} \mathrm{C}\right)\end{array}$} & \multirow[t]{2}{*}{ Sample } & \multirow[t]{2}{*}{$\mathrm{DS}^{\mathrm{d}}$} & \multicolumn{2}{|c|}{ Solubility ${ }^{\mathrm{e}}$} \\
\hline & & & & & & & Water & DMSO \\
\hline $1 \mathrm{a}$ & DMA/LiCl & $1: 1: 2$ & 24 & 50 & 2 & 0.35 & + & + \\
\hline $1 b$ & DMA/LiCl & $1: 1: 2$ & 20 & 50 & 3 & 0.33 & + & + \\
\hline $1 b$ & DMA/LiCl & $1: 3: 6$ & 20 & 50 & 4 & 0.58 & + & + \\
\hline $1 b$ & BMIMCl & $1: 1: 2$ & 2 & 80 & 5 & 0.08 & - & - \\
\hline $1 b$ & BMIMCl & $1: 3: 6$ & 2 & 80 & 6 & 0.41 & - & + \\
\hline $1 b$ & BMIMCl & $1: 5: 10$ & 2 & 80 & 7 & 0.18 & - & - \\
\hline $1 b$ & EMIMAc & $1: 1: 2$ & 2 & 80 & 8 & 0.13 & + & + \\
\hline $1 b$ & EMIMAc & $1: 3: 6$ & 2 & 80 & 9 & 0.08 & + & + \\
\hline
\end{tabular}

a 1a Degraded cellulose, degree of polymerization, DP, 30; 1b microcrystalline cellulose, DP $270{ }^{\mathrm{b}} \mathrm{N}, N$-Dimethyl acetamide (DMA), 1-N-butyl-3-methylimidazolium chloride (BMIMCl), 1 $N$-ethyl-3-methylimidazolium acetate (EMIMAc). ${ }^{\mathrm{c}}$ Molar ratio anhydroglucose unit: 2,3,4,6tetraacetyl-1-bromo- $\alpha$-D-glucopyranoside: triethylamine. ${ }^{\mathrm{d}}$ Degree of substitution. ${ }^{\mathrm{e}}$ Dimethyl sulphoxide (DMSO), soluble (+), insoluble (-).

Increasing the molar ratio to AGU:2,3,4,6-tetraacetyl-1-bromo- $\alpha$-D-gluco-pyranoside: triethylamine 1:3:6 lead to an increase of the DS to 0.58 (sample 4). This sample is also soluble in water and DMSO. Obviously, no further increase of the DS was possible. The reaction of cellulose dissolved in BMIMCl was carried out for $2 \mathrm{~h}$ at $80{ }^{\circ} \mathrm{C}$. No reaction occurred at a molar ratio AGU: 2,3,4,6-tetraacetyl-1-bromo- $\alpha$-D-gluco-pyranoside:triethylamine of 1:1:2. Increasing the molar ratio to 1:3:6 resulted in a product with DS 0.41 (Table 1, sample 6) that was soluble in DMSO but insoluble in water. Further increase of the molar ratio to 1:5:10 afforded a product with smaller DS (0.18, sample 7).

The FTIR spectrum of sample 4 shows all typical structural features of a cellulose derivative (spectrum not shown). Thus, a broad absorption band around $3479 \mathrm{~cm}^{-1}$ indicated the presence of hydroxyl groups as expected with respect to the low DS of 0.58 . The band at $2957 \mathrm{~cm}^{-1}$ is attributed to the $\mathrm{CH}$ moieties in the molecule. The intensive carbonyl band at $1747 \mathrm{~cm}^{-1}$ evidenced the presence of the acetylated glucose moieties attached to the cellulose backbone. Moreover, the C-O-C valence vibrations could be found at $1245 \mathrm{~cm}^{-1}$ (ester) and $1042 \mathrm{~cm}^{-1}$ (AGU).

${ }^{13} \mathrm{C}$ NMR spectroscopy revealed the presence of glucose moieties attached to the cellulose backbone (sample 2, Figure 1). The signal at $20.8 \mathrm{ppm}$ was attributed to the methyl group of the acetyl moiety at the attached glucose moiety. Various peaks appeared in the range between 60 and $103 \mathrm{ppm}$ that are caused by both the cellulose backbone and the attached acetyl glucose 
moiety. Unfortunately, it was not possible to distinguish between signals from backbone and the sugar moieties attached.

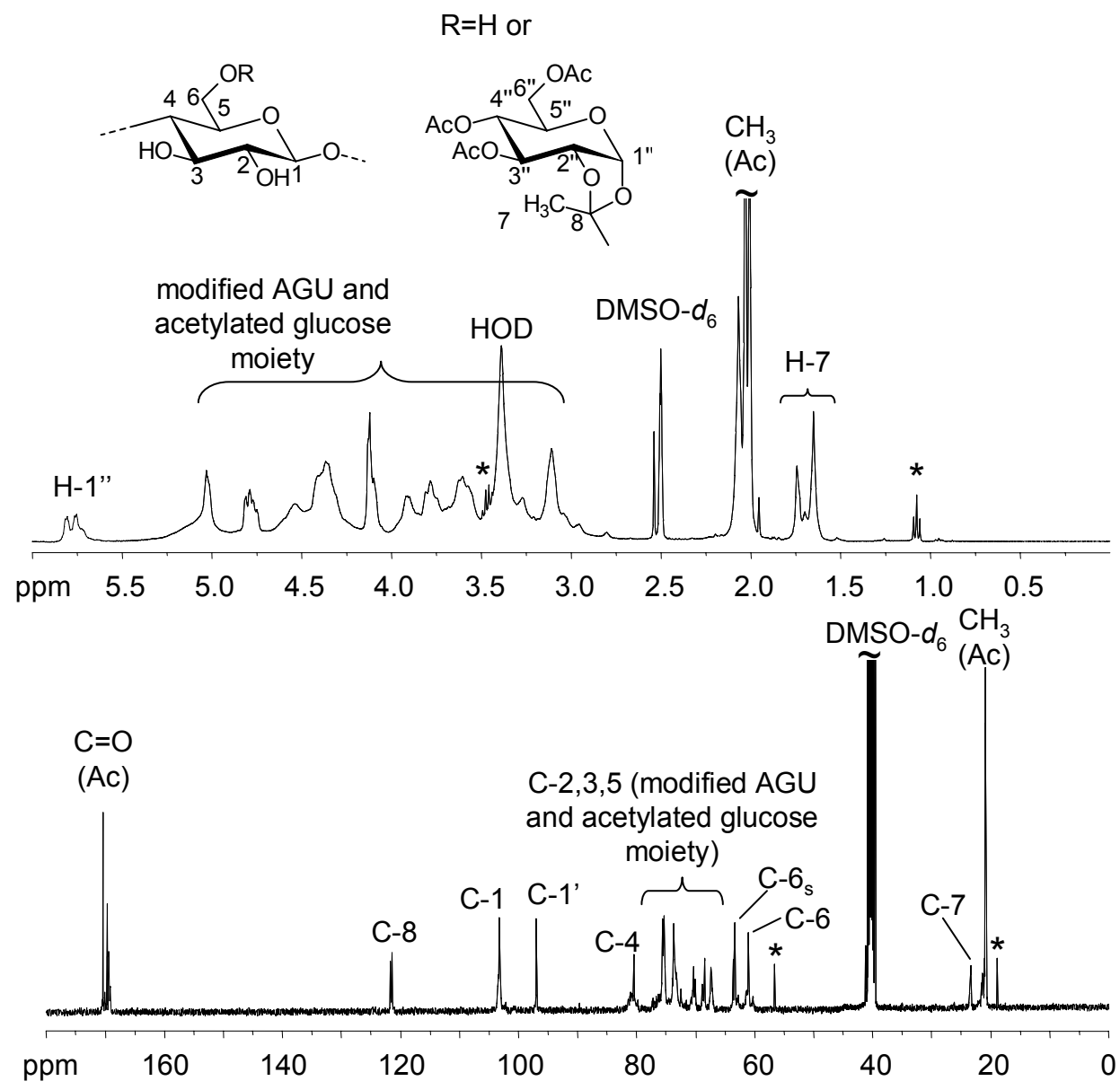

Figure 1. ${ }^{1} \mathrm{H}$ - (top) and ${ }^{13} \mathrm{C}-\mathrm{NMR}$ spectrum (bottom) of cellulose reacted with 2,3,4,6tetraacetyl-1-bromo- $\alpha$-D-glucopyranoside in the presence of triethylamine (sample 2), recorded in dimethyl sulphoxide (DMSO)- $d_{6}$. Not assigned signals are marked with an asterisk (Ac= Acetyl).

However, a signal at $97.0 \mathrm{ppm}$ is characteristic for the C-1 of a single sugar molecule, while the peak at $103.2 \mathrm{ppm}$ belongs to the carbon atom of position 1. A set of signals at 169.1$170.4 \mathrm{ppm}$ was assigned as carbonyl carbon atoms of the acetyl glucose moiety. According to Tsui and Gorin, ${ }^{29}$ orthoesters can be formed from 2,3,4,6-tetraacetyl-1-bromo- $\alpha$-Dglucopyranoside and hydroxyl compounds. The carbon atom of the orthoester (C-8) could be detected at a chemical shift of 121.4 and $121.7 \mathrm{ppm}$. Moreover, the peak at $23.4 \mathrm{ppm}$ was accordingly assigned as the corresponding methyl group (C-7). This finding was supported by the ${ }^{1} \mathrm{H}-\mathrm{NMR}$ spectrum of sample 2 (Figure 1) showing signals at 5.81 and $5.75 \mathrm{ppm}(\mathrm{H}-1$ ") as well as at 1.75 and $1.65 \mathrm{ppm}$ (H-7, orthoester). Although the peaks of H-1" and H-7 are not 
baseline separated, the integral ratio is almost equal to $1: 3$, and corresponds with the expected value for the orthoester.

The chemical shifts of both the polymer backbone and the acetylated glucose moieties are very similar, and, hence, it was impossible to distinguish between them. Therefore, the ${ }^{13} \mathrm{C}-\mathrm{NMR}$ spectrum looks like the spectrum of a cellulose acetate. Two-dimensional NMR measurements of the perpropionylated sample did not yield more information on the structure.

Therefore it was interesting to investigate if there are sugar molecules that are incorporated in the polymer structure without being chemically bound. Diffusion measurements (DOSY) and $\mathrm{T}_{2}$ filter techniques on sample 2 were utilized to ensure that all signals detected in the NMR spectra belong to the polymer. The signals of ethanol were used as reference. Applying the $\mathrm{T}_{2}$ filter technique, the intensity of signals of small molecules with high $\mathrm{T}_{2}$ was less damped compared with the signals of the polymer (Figure $2 b$ ). This finding was underpinned by the DOSY technique (Figure 2a).

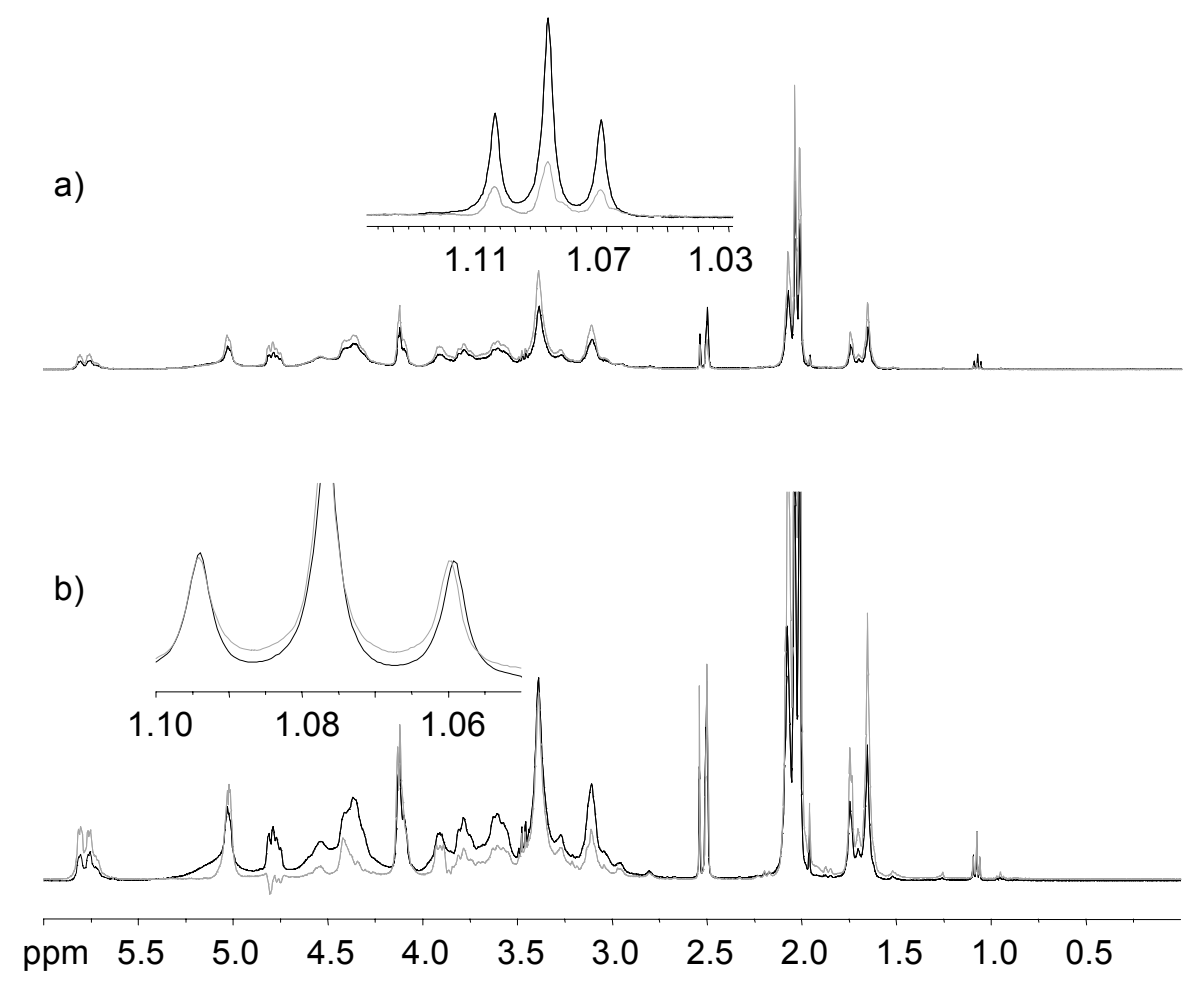

Figure 2. DOSY - (a) and $\mathrm{T}_{2}-\mathrm{NMR}$ experiments (b) of sample 2 recorded in dimethyl sulphoxide- $d_{6}$. The inserts show the methyl group signals of ethanol as reference. Standard spectrum (black line), diffusion/ $\mathrm{T}_{2}$-filtered spectrum (grey line).

Here, small molecules leave the diffusion gradient faster than the polymer and, hence, the ethanol signals loose their intensity compared with the signals of the polymer. Due to the fact that NMR studies did not gave sufficient structural information, sample 4 (DS 0.58) was subjected to methylation analysis in order to gain information on the composition of the 
polysaccharide derivatives studied (Table 2). The content of 1,4-linked AGUs was determined to be $33.9 \%$, which is attributed to non-functionalized AGUs of the polymer backbone (Figure 3 ). The amount of 1-4,6-linked AGUs, i.e., 6- $O$-functionalized AGUs was 16.3\%. The linkage types 1-3,4 (i.e., 3- $O$-glycosylated, 3.7\%), 1-2,4 (i.e., 2- $O$-glycosylated, 3.1\%), 1-3,4,6 (i.e., 3,6-di- $O$ glycosylated, 1.9\%), 1-2,4,6 (i.e., 2,6-di-O-glycosylated, 1.6\%) were found as well. It can be concluded that the reaction occurred predominantly at position 6 . Reactions at positions 2 and 3 as well as multiple glycosylations were less pronounced. Terminal glucose moieties (T-Glc) can be either end groups of the polymer backbone itself or the glucose moieties attached to it. Due to the low amount of $4.9 \%$, the content of end groups was expectedly low but also the content of glycosyl branches is low. An interesting finding was the occurrence of 34.6\% of 1-2-linkages, which corresponds to a glycosidic bond at position 1 and a linkage at position 2 of a single glucose moiety. This is in agreement with the formation of a 1,2-orthoester structure, which simultaneously blocks positions 1 and 2 of the glucose molecule.

The ${ }^{13} \mathrm{C}$-NMR spectrum of sample 6 synthesized in $\mathrm{BMIMCl}$ shows the signals of a cellulose derivative bearing acetylated glucose moieties, i.e., an additional peak for C-1' appeared at 96.7 ppm (Figure 4, top).

Table 2. Results of methylation analysis of samples 3 (degree of substitution, DS, 0.33) and 4 (DS 0.58)

\begin{tabular}{ccc}
\hline Linkage type $^{\mathrm{a}}$ & \multicolumn{2}{c}{ Sample } \\
\cline { 2 - 3 } & $\mathbf{4}$ & $\mathbf{3}$ \\
\hline T-Glc & $4.9 \%$ & $10.9 \%$ \\
$1-2$ & $34.6 \%$ & $20.3 \%$ \\
$1-4$ & $33.9 \%$ & $63.6 \%$ \\
$1-3,4$ & $3.7 \%$ & - \\
$1-2,4$ & $3.1 \%$ & $0.6 \%$ \\
$1-4,6$ & $16.3 \%$ & $4.6 \%$ \\
$1-3,4,6$ & $1.9 \%$ & - \\
$1-2,4,6$ & $1.5 \%$ & - \\
\hline
\end{tabular}

${ }^{\mathrm{a}}$ See Figure 3.

Interestingly, this signal is missing in the ${ }^{13} \mathrm{C}-\mathrm{NMR}$ spectrum of sample $\mathbf{8}$, prepared in EMIMAc. On the contrary, the ${ }^{13} \mathrm{C}-\mathrm{NMR}$ spectrum of $\mathbf{8}$ is comparable to a cellulose acetate (Figure 4, bottom). Obviously, the IL EMIMAc did not act as solvent only, but also it forced acetylation of the dissolved cellulose. This behavior has already been described in literature regarding reaction of cellulose with carboxylic acid chlorides, $p$-toluenesulphonic acid chloride and triphenylchloromethane. ${ }^{28}$ Thus, reactions in $\mathrm{BMIMCl}$ are possible but lead to products with lower DS compared with reactions in $\mathrm{DMA} / \mathrm{LiCl}$. Moreover, use of EMIMAc as solvent is not 
recommended due to the predominant occurrence of acetylation instead of the orthoester formation.

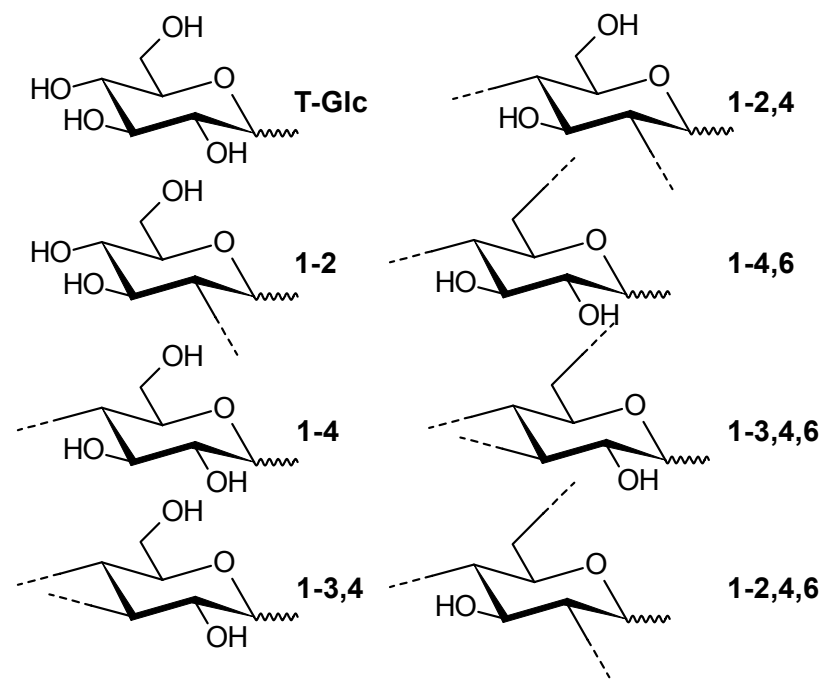

Figure 3. Linkage types in cellulose derivatives determined by methylation analysis.

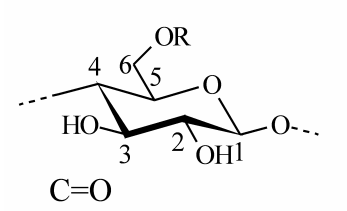

(Ac)

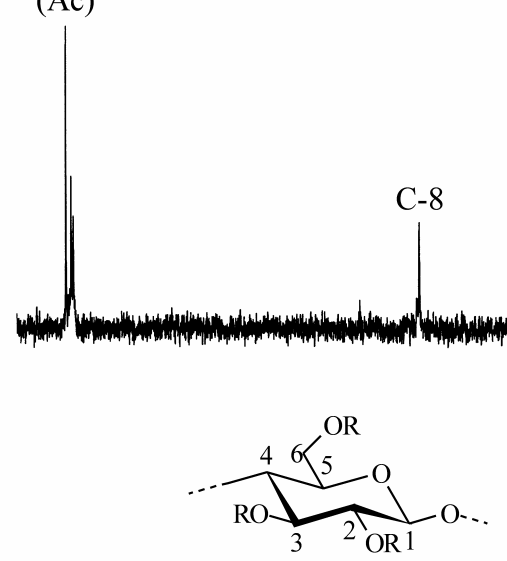

$\mathrm{C}=\mathrm{O}$
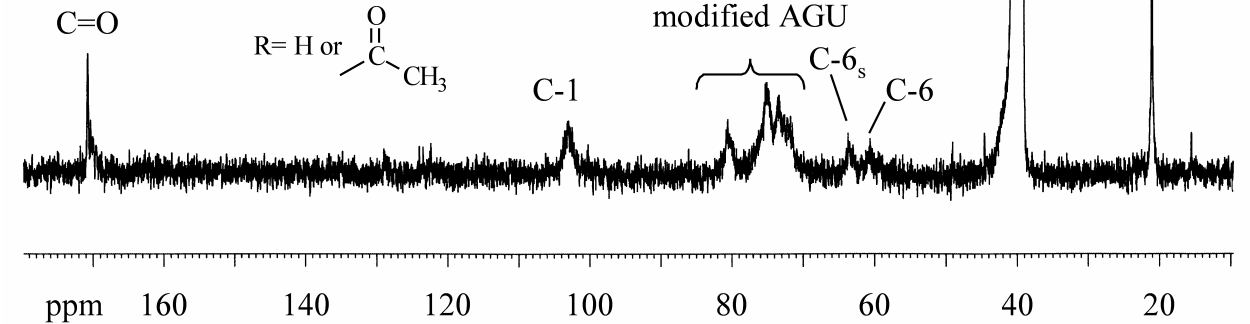

Figure 4. ${ }^{13} \mathrm{C}$-NMR spectrum of sample 6 (top, synthesized in $1-N$-butyl-3-methylimidazolium chloride) and 8 (bottom, synthesized in 1- $N$-ethyl-3-methylimidazolium acetate) recorded in dimethyl sulphoxide- $d_{6}$. Not assigned signals are marked with an asterisk (Ac $=$ Acetyl). 
The products were treated with an ethanolic $\mathrm{NaOH}$ solution to remove the acetyl moieties in a heterogeneous procedure. The products became insoluble in DMSO but dissolved in diluted $\mathrm{NaOH}$. The ${ }^{1} \mathrm{H}-\mathrm{NMR}$ spectrum of sample 10 revealed complete deacetylation due to the absence of the signal at $2 \mathrm{ppm}\left(\mathrm{CH}_{3}\right.$ of the acetyl group, Figure 5, top). The protons of the AGU were detected in the range from $3-5 \mathrm{ppm}$. The signal at $5.68 \mathrm{ppm}$ was assigned to $\mathrm{H}-1$ of the attached glucose residue in $\alpha$-configuration according to Liebert et al. ${ }^{30}$

The ${ }^{13} \mathrm{C}-\mathrm{NMR}$ spectrum of $\mathbf{1 0}$ is similar to that of $\mathbf{4}$ except the acetyl signals (Figure 5, bottom). Following signals appear: $121.1 \mathrm{ppm}$ (C-8), 103.6, $102.2 \mathrm{ppm}$ (C-1, C-1*), $97.6 \mathrm{ppm}$ (strong signal, C-1"), 79.0-70.6 ppm (C-2,3,4,5), 62.2 ppm (C-6s), 60.7 ppm (C-6), 22.1, $21.2 \mathrm{ppm}(\mathrm{C}-7)$.

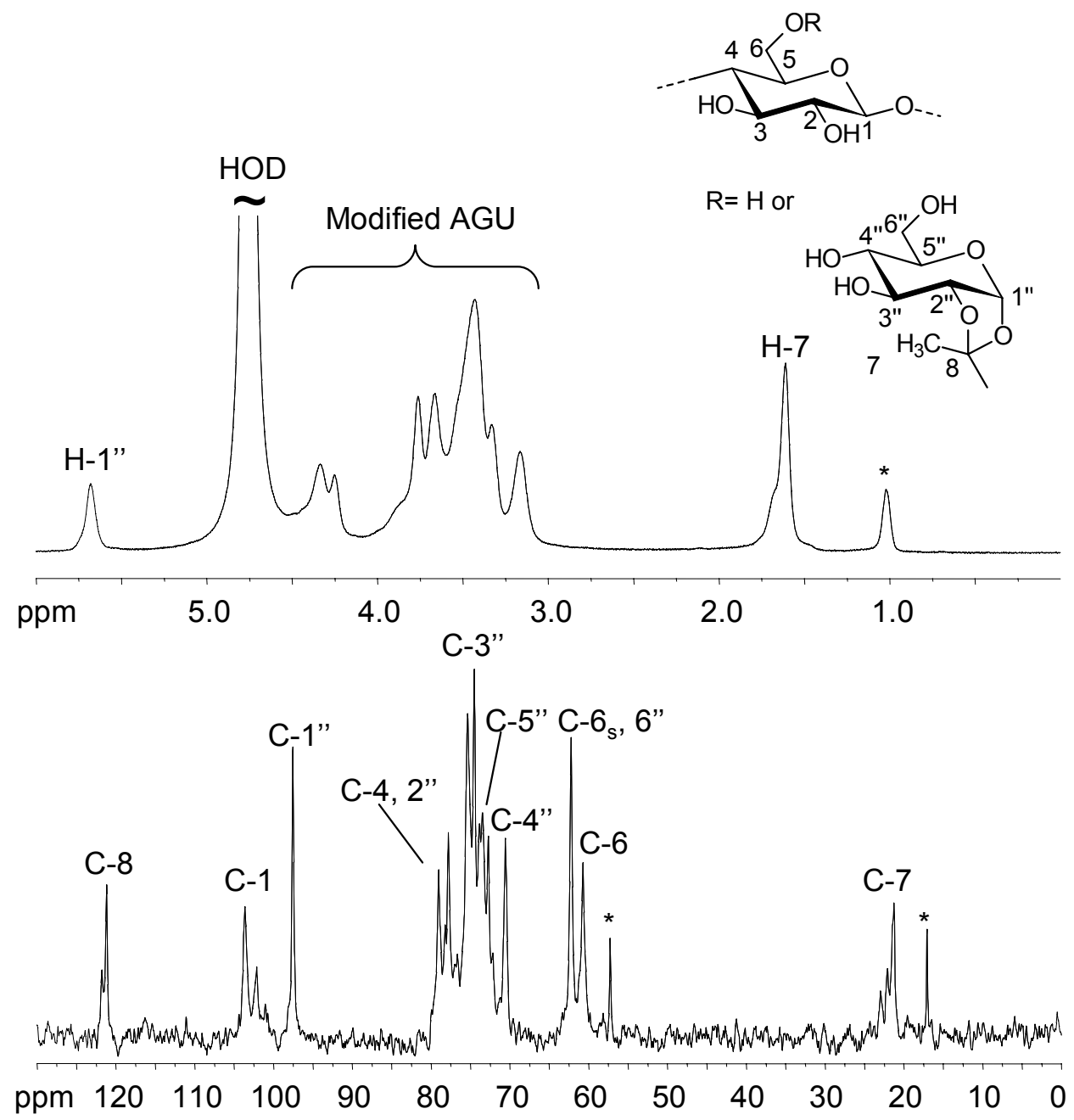

Figure 5. ${ }^{1} \mathrm{H}-\mathrm{NMR}$ - (top) and ${ }^{13} \mathrm{C}-\mathrm{NMR}$ spectra (bottom) of sample $\mathbf{1 0}$ obtained by saponification of $\mathbf{4}$ (recorded in $\mathrm{D}_{2} \mathrm{O} / \mathrm{NaOD}$ ). Not assigned signals are marked with an asterisk.

The peaks of the glucose moiety attached are hard to assign. However, the occurrence of some signals could be confirmed by comparison with published NMR data of 1,2-methyl 
orthoacetyl- $\alpha$-D-glucopyranose: 112.9 ppm (C-8), 98.6 ppm (C-1"), 79.6 ppm (C-2"), 74.9 ppm (C-3"), 74.7 ppm (C-5"), 70.2 ppm (C-4"), 63.0 ppm (C-6"), 23.8 ppm C-7). ${ }^{31}$ These results indicated that the orthoester remained intact under the alkaline conditions applied for the deacetylation.

\section{Conclusions}

It was shown that the reaction of cellulose with 2,3,4,6-tetraacetyl-1-bromo- $\alpha$-D-glucopyranoside in the presence of triethylamine yields derivatives bearing glucose moieties attached via 1,2orthoesters instead of a glycosidic bond, that was proved by NMR studies and methylation analysis. These derivatives are soluble in aprotic-dipolar media and at a DS of about 0.3 also in water. Water soluble derivatives are interesting products for viscosity control of aqueous media. Moreover, it is expected that this method can be used to attach other sugar moieties onto cellulose to mimic biologically active complex polysaccharides.

\section{Experimental Section}

General. The microcrystalline cellulose (Avicel®, DP 270) purchased from Sigma Aldrich (Munich, Germany) and a cellulose sample with DP 30 (obtained by acidic hydrolysis of cellulose according to Meiland et al. ${ }^{32}$ ) were dried in vacuum over potassium hydroxide at $105^{\circ} \mathrm{C}$. Lithium chloride (Sigma Aldrich, Munich, Germany) was dried in vacuum at $150^{\circ} \mathrm{C}$ over potassium hydroxide. The ionic liquids BMIMCl and EMIMAc were purchased from IoLiTec $\mathrm{GmbH}$ (Heilbronn, Germany) and used as received. Triethylamine (Sigma Aldrich, Munich, Germany) was dried over calcium hydride and distilled prior to use. All other reagents were used as received. FTIR spectra were recorded on a Nicolet AVATAR 370 DTGS spectrometer using the KBr-technique. 1D- and 2D-NMR spectra were measured on a Bruker AVANCE 400 NMR spectrometer (400 MHz, Rheinstetten, Germany) with Bruker standard pulse programs and processed with MestReNova software package as well as XWINNMR. The solvents used were DMSO- $d_{6}$ and $\mathrm{CDCl}_{3}$ at temperatures between 45 and $60{ }^{\circ} \mathrm{C}$.

The glycosidic linkage analysis was determined by methylation and gas chromatographymass spectroscopy (GC-MS). Methylation of the polymers was carried out according to the procedure previously described ${ }^{33}$ followed by GC-MS analysis of the partially methylated alditol acetates. $^{34,35}$

The acetyl group content was determined according to Tanghe et al. ${ }^{36}$ Calculation of the acetyl group content is performed according to equation 1 and the DS is calculated according to equation 2 . 


$$
\operatorname{Ac}(\%)=\frac{\left(\mathrm{V}_{\mathrm{NaOH}}-\mathrm{V}_{\mathrm{HCl}}+\mathrm{V}_{\mathrm{Blind}}\right) \cdot 2.15}{\mathrm{~m}_{\text {Sample }}}
$$

Ac(\%): Acetyl group content in \%

$\mathrm{V}_{\mathrm{NaOH}}$ : Amount of $\mathrm{NaOH}$, from back titration

$\mathrm{V}_{\mathrm{HCl}}$ : Amount of $\mathrm{HCl}$, from titration

$\mathrm{V}_{\text {Blind: }} \mathrm{NaOH}$ consumed by titration of $40 \mathrm{~mL} \mathrm{HCl}$ (as blind value).

$$
\mathrm{DS}=\frac{\mathrm{M}_{\mathrm{AGU}} \cdot \operatorname{Ac}(\%)}{4 \cdot \mathrm{M}_{\mathrm{Ac}} \cdot 100-\mathrm{M}_{\text {Subst. }} \cdot \operatorname{Ac}(\%)}
$$

DS: Degree of substitution

$\mathrm{M}_{\mathrm{AGU}}$ : Molar mass of the anhydroglucose unit, $161.14 \mathrm{~g} \mathrm{~mol}^{-1}$

Acc(\%): Acetyl group content in \%

$\mathrm{M}_{\mathrm{Ac}}$ : Molar mass of the acetyl group, $43 \mathrm{~g} \mathrm{~mol}^{-1}$

$\mathrm{M}_{\text {Subst. }}$ : Molar mass of the substituent, $331.316 \mathrm{~g} \mathrm{~mol}^{-1}$.

1,2,3,4,6-Pentaacetyl-D-glucose. 1,2,3,4,6-Pentaacetyl-D-glucose was prepared according to a common procedure (mixture of $\alpha$ - and $\beta$-anomer, melting at $\left.98-99^{\circ} \mathrm{C}\right)^{37}$

2,3,4,6-Tetraacetyl-1-bromo- $\alpha$-D-glucopyranoside (adapted from ${ }^{38)}$. 1,2,3,4,6-Pentaacetyl-Dglucpyranoside $(70.2 \mathrm{~g}, 0.180 \mathrm{~mol})$ was mixed with $208 \mathrm{~mL} \mathrm{HBr} /$ glacial acetic acid $(32 \%$ solution) in a flask equipped with magnetic stirrer and bubbler. After $2 \mathrm{~h}$ at room temperature, the clear yellow solution was diluted with $500 \mathrm{~mL}$ chloroform, poured into $500 \mathrm{~mL}$ ice-water and stirred for additional $10 \mathrm{~min}$. The organic layer was separated, washed with aqueous sodium thiosulphate $(0.5 \%, \mathrm{w} / \mathrm{w})$, saturated $\mathrm{NaHCO}_{3}$ solution and water. After drying over $\mathrm{Na}_{2} \mathrm{SO}_{4}$, the solvent was evaporated and the yellowish syrup was recrystallized from $400 \mathrm{~mL}$ diethyl ether/nhexane (8.5:1.5) yielding 2,3,4,6-tetraacetyl-1-bromo- $\alpha$-D-glucopyranoside as colorless needles. The product is stored in the freezer at $-18^{\circ} \mathrm{C}$ under exclusion of light and moisture. Yield: $39 \mathrm{~g}$ $\left(53 \%\right.$, melting point $\left.90^{\circ} \mathrm{C}\right) . \delta_{\mathrm{H}}(400 \mathrm{MHz}) 2.01\left(\mathrm{CH}_{3}\right), 4.22(\mathrm{H}-6), 4.27(\mathrm{H}-5), 4.33(\mathrm{H}-6), 4.77$ (H-2), $5.10(\mathrm{H}-4), 5.52(\mathrm{H}-3), 6.57(\mathrm{H}-1) ; \delta_{\mathrm{C}}(100 \mathrm{MHz}) 20.6,20.5\left(\mathrm{CH}_{3}\right), 61.0(\mathrm{C}-6), 67.1$ (C4), 70.1 (C-5), 70.6 (C-2), $72.1(\mathrm{C}-3), 86.6(\mathrm{C}-1), 169.4-170.5(\mathrm{C}=\mathrm{O})$.

Reaction of cellulose dissolved in DMA/LiCl with 2,3,4,6-tetraacetyl-1-bromo- $\alpha$-Dglucopyranoside. Cellulose (DP 30, $1.54 \mathrm{~g}, 0.0095 \mathrm{~mol}$ ) was stirred with $30 \mathrm{~mL}$ of DMA for $2 \mathrm{~h}$ at $120^{\circ} \mathrm{C}$ under exclusion of moisture. After cooling to $100^{\circ} \mathrm{C}, 2.0 \mathrm{~g}$ of anhydrous $\mathrm{LiCl}$ were added and stirring was continued until complete dissolution of the polymer. A mixture of $2.63 \mathrm{~mL}(0.018 \mathrm{~mol})$ triethylamine and $3.0 \mathrm{~mL}$ DMA was added to the cellulose solution at room temperature followed by $3.90 \mathrm{~g}(0.009 \mathrm{~mol})$ 2,3,4,6-tetraacetyl-1-bromo- $\alpha$-D-glucopyranoside dissolved in $5.0 \mathrm{~mL}$ DMA. The mixture was allowed to react for $24 \mathrm{~h}$ at $50^{\circ} \mathrm{C}$ under stirring. The reddish brown mixture was cooled down and poured into $500 \mathrm{~mL}$ ethanol. The precipitated polymer was collected, washed with ethanol, and dried in vacuum at $60^{\circ} \mathrm{C}$.Yield: $2.0 \mathrm{~g}$ (sample 2). $\delta_{\mathrm{H}}(400 \mathrm{MHz}) 2.01 \mathrm{ppm}\left(\mathrm{CH}_{3}\right), 2.80-5.8 \mathrm{ppm}$ (modified AGU, acetylated glucose moieties); 
$\delta_{\mathrm{C}}(100 \mathrm{MHz}) 20.8\left(\mathrm{CH}_{3}\right), 23.4(\mathrm{C}-7) 61.1$ (C-6), 63.4 (C-6s), 67.3-80.4 (C-2,3,4,5 of the modified AGU), 97.0 (C-1, side-chain), 103.2 (C-1, backbone), 121.4, 121.7 (C-8), 169.1-170.4 $(\mathrm{C}=\mathrm{O})$. The sample was soluble in water, DMA, and DMSO.

Reaction of cellulose dissolved in BMIMCl with 2,3,4,6-tetraacetyl-1-bromo- $\alpha$-Dglucopyranoside. A mixture of cellulose (1b $0.5 \mathrm{~g}, 0.003 \mathrm{~mol})$ and $4.5 \mathrm{~g} \mathrm{BMIMCl}$ was stirred overnight at $80^{\circ} \mathrm{C}$ until complete dissolution of the polymer. After addition of $2.5 \mathrm{~mL}$ $(0.018 \mathrm{~mol})$ triethylamine, stirring was continued for $10 \mathrm{~min}$ at $80^{\circ} \mathrm{C} .2,3,4,6$-tetraacetyl-1bromo- $\alpha$-D-glucopyranoside $(4.08 \mathrm{~g}, 0.09 \mathrm{~mol})$ were added and the mixture was allowed to react for $2 \mathrm{~h}$ at $80^{\circ} \mathrm{C}$ under stirring. The polymer was isolated by precipitation in ethanol, washing with ethanol, and drying in vacuum at $60^{\circ} \mathrm{C}$. Yield: $0.89 \mathrm{~g}$ (sample 6) DS (calculated from theoretical assumptions): 0.41. v $(\mathrm{KBr}) 3446(\mathrm{OH}), 1749(\mathrm{C}=\mathrm{O}), 1374\left(\mathrm{CH}_{3}\right), 1234\left(\mathrm{C}-\mathrm{O}-\mathrm{C}_{\text {Ester }}\right)$, $1042\left(\mathrm{COC}_{\mathrm{AGU}}\right) ; \delta_{\mathrm{H}}(400 \mathrm{MHz}) 1.61(\mathrm{C}-7), 2.0-2.06\left(\mathrm{CH}_{3}\right), 3.0-6.65(\mathrm{H}-1,2,3,4,5,6$ modified AGU); $\delta_{\mathrm{C}}(100 \mathrm{MHz}) 21.0\left(\mathrm{CH}_{3}\right), 60.7(\mathrm{C}-6), 63,3(\mathrm{C}-6 \mathrm{~s}), 66.9-80.7(\mathrm{C}-2,3,4,5$ of the modified AGU), 96.7 (C-1, side-chain), 103.3 (C-1, backbone), 121.2 (C-8), 169.6-170.7 (C=O). The sample was soluble in DMSO and insoluble in water.

Saponification of sample 4. Sample $4(2.0 \mathrm{~g})$ was suspended in a solution of $2.5 \mathrm{~g}$ potassium hydroxide and $50 \mathrm{~mL}$ of ethanol. The mixture was allowed to react for $24 \mathrm{~h}$ at $50^{\circ} \mathrm{C}$ under stirring in argon atmosphere. The polymer was separated by centrifugation, slurried in ethanol and neutralized with acetic acid. Impurities were removed by washing with aqueous ethanol $(90: 10, \mathrm{v} / \mathrm{v})$ and the product was dried in vacuum at $60^{\circ} \mathrm{C}$. Yield: $1.2 \mathrm{~g}$ (sample 10). $\delta_{\mathrm{H}}$ (400 MHz) 1.61 (C-7), 3.17-5.68 (H-1,2,3,4,5,6 modified AGU); $\delta_{\mathrm{C}}(100 \mathrm{MHz}) 121.1 \mathrm{ppm}(\mathrm{C}-$ 8), 103.6, 102.2 ppm (C-1, C-1*), 97.6 (strong signal, C-1"), 79.0-70.6 (C-2,3,4,5), 62.2 (C-6s), 60.7 (C-6), 22.1, 21.2 (C-7). The sample was soluble in aqueous $\mathrm{NaOH}$.

\section{Acknowledgements}

The authors wish to thank the Wolff Cellulosics GmbH \& Co. KG for the financial support. The authors thank M. Meiland (Friedrich Schiller University of Jena) for preparing the cellulose with degree of polymerization of 30 and Dr. W. Günther (Friedrich Schiller University of Jena) for conducting the NMR measurements

\section{References}

1. Klemm, D.; Schmauder, H. P.; Heinze, Th. (2002) in Biopolymers: Biology, Chemistry, Biotechnology, Applications. DeBaets, S.; Vandamme, E. J.; Steinbüchel A. Eds; WileyVCH: Weinheim, 2002; pp 275.

2. Greenway, T. M. In Cellulosic polymers, blends, and composites. Gilbert, R. D. Ed.; Carl Hanser Verlag: Munich, 1994; pp 173. 
3. Ott, C. M., Day, D. F. Plast. Eng. 2000, 60, 185.

4. Neely, W. B. U.S. Patent 3133 856, 1964; Chem. Abstr. 1964, 61, 33538.

5. Frazier, C. E.; Wendler, S. L; Glasser W. Carbohydr. Polym. 1996, 31, 11.

6. Pfannemüller, B.; Richter, G. C.; Husemann, E. Carbohydr. Res. 1975, 43, 151.

7. Nakamura, S.; Saegusa, Y.; Watanabe, K. J. Polym. Sci., Part C: Polym. Lett. 1990, $28,53$.

8. Pfannemüller, B.; Richter, G. C.; Husemann, E. Carbohydr. Res. 1977, 56, 147.

9. Pfannemüller, B.; Richter, G. C.; Husemann, E. Carbohydr. Res. 1977, 56, 139.

10. Kurita, K.; Kobayashi, M.; Munakata, T.; Ishii, S.; Nishimura. S.-I. Chem. Lett. 1994, 11, 2063.

11. Kurita, K. Adv. Chitin Sci. 1997, 2, 320.

12. Kurita, K.; Akao, H.; Kobayashi, M.; Mori, T.; Nishiyama Y. Polym. Bull. 1997, 39, 543.

13. Kurita, K.; Kojima, T.; Munakata, T.; Akao, H.; Mori, T.; Nishiyama, Y.; Shimojoh, M. Chem. Lett. 1998, 4, 317.

14. Matsuzaki, K.; Yamamoto, I.; Enomoto, K.; Kaneko, Y.; Mimura, T.; Shiio, T. Polymer. Mater. Sci. Eng. 1987, 57, 296.

15. Matsuzaki, K.; Yamamoto, I.; Sato, T.; Oshima, R. Makromol. Chem. 1986, 187, 325.

16. Kurita, K.; Kojima, T.; Nishiyama, Y.; Shimojoh, M. Macromolecules 2000, 33, 4711.

17. Vieira, M.; Heinze, Th. Polym. News 2001, 26, 274.

18. Koschella, A.; Heinze, Th. Macromol. Biosci. 2001, 1, 178.

19. Heinze, Th.; Schaller, J. Macromol. Chem. Phys. 2000, 201, 1214.

20. Heinze, Th.; Pfeiffer, K. Angew. Makromol. Chem. 1999, 266, 37.

21. Koschella, A.; Richter, M.; Heinze, Th. Carbohydr. Res. 2010, 345, 1028.

22. Dawsey, T. R. In Cellulosic Polymers, Blends, and Composites. Gilbert, R. D. Ed.; Hanser Publ.: Munich, 1994; pp 157.

23. El Seoud, O.; Koschella, A.; Fidale, L. C.; Dorn, S.; Heinze, Th. Biomacromolecules 2007, $8,2629$.

24. Barthel, S.; Heinze, Th. Green Chem. 2006, 8, 301.

25. Köhler, S.; Heinze, Th. Cellulose 2007, 14, 489.

26. Gericke, M.; Liebert, T.; Heinze Th. Macromol. Biosci. 2009, 9, 343.

27. Köhler, S.; Liebert, T.; Heinze, Th.; Vollmer, A.; Mischnick, P.; Möllmann, E.; Becker W. Cellulose 2010, 17, 437.

28. Köhler, S.; Liebert, T.; Schöbitz, M.; Schaller, J.; Meister, F.; Günther, W.; Heinze, Th. Macromol. Rapid Commun. 2007, 28, 2311.

29. Tsui, D. S. K.; Gorin, P. A. J. Carbohydr. Res. 1985, 144, 137.

30. Liebert, T.; Seifert, M.; Heinze Th. Macromol. Symp. 2008, 262, 140.

31. Moradei, O.; Leit, S.; du Mortier, C.; Fernández Cirelli, A.; Thiem J. J. Carbohydr. Chem. 1993, 12, 13.

32. Meiland, M.; Liebert, T.; Heinze Th. Macromol. Mater. Eng. 2011, $296,802$.

33. Kim, J. B.; Carpita, N. C. Plant Physiol. 1992, 98, 646. 
34. Samuelsen, A. B.; Paulsen, B. S.; Wold, J. K.; Otsuka, H.; Yamada, H.; Espevik, T. Phytother. Res. 1995, 9, 211.

35. Barsett, H.; Paulsen, B. S.; Habte, Y. Carbohydr. Polym. 1992, 18, 125.

36. Tanghe, L. J.; Genung, L. B.; Mench, J. W. Meth. Carbohydr. Chem. 1963, 3, 201.

37. Beckert, R.; Fanghänel, E.; Habicher W. D.; Metz, P.; Pavel, D.; Schwetlick, K. Organikum: Organisch-Chemisches Grundpraktikum.; Wiley-VCH: Weinheim, 2004; 22nd Ed, pp 477.

38. Redemann, E. C.; Niemann, C. Org. Synth., Coll. Vol. 1955, 3, 11. 